\title{
THE USE OF THE GRADED RESPONSE MODEL (GRM) IN THE PROCESS OF THE ASSESSMENT OF THE PSYCHOLOGICAL CONTENT OF WORK AMONG EMPLOYEES
}

Purpose: the objective of this paper is to analyze the possibility of the use of GRM in evaluating the psychological content of the work among employees. Design/methodology/ approach: the study was conducted on a sample of 500 employees in a mining company with the use of a standardized JCQ questionnaire by R. Karasek. The study is based on adapting existing scientific theories, according to which GRM is used for the purpose of solving problems, combined with the application of the GRM for the analysis of empirical material. Findings: the findings and comparisons show that the GRM can be useful in the employee assessment process. The model allowed to find relevant differences between employees who achieved the same results in JCQ. This led to establishing a valid diagnosis in employee's resources and demands. Furthermore, it can be claimed that, in some cases, more detailed solutions were obtained with the use of the GRM, facilitating in a further stage making decisions and planning actions in order to identify the factors determining the improvement of working conditions and affecting employee motivation. Implications: in the presented study, the GRM was used for an in-depth analysis of job content and employee resources as diagnosed by Karasek's JCQ. In the second part of the article the results were applied to suggest a better organization of work to facilitate the development of individual potential. The ideas were successfully implemented during the work-related health promotion program in the company. Originality/value: such an analysis is rarely considered in the literature. It can provide useful information about employee performance and potential.

Keywords: GRM, latent trait model, employee potential, psychological content of work, Karasek

DOI: $10.15611 /$ aoe.2019.1.12

\section{INTRODUCTION}

The thesis that an employee is the main factor determining competetiveness, and that human capital is one of the most important resources of an organization, has already become the canon in the theories of human resources management. The activities supporting employee development in

\footnotetext{
* Wrocław University of Economics.
} 
the scope of formal as well as interpersonal qualifications are obvious, however, not always adequately appreciated. That development, understood as an organization operation preparing an employee to learn, develop and hold more and more responsible positions (Armstrong, 1999; Torrington, Hall, Taylor, Atkinson 2014), also includes care for the well-being and the optimum professional health level through examining and improving the psychological qualities of work affecting work motivation and dedication (Molek-Winiarska, 2016). The organizations which realize the value of their motivated and dedicated employees try to identify their possibilities and weaknesses as precisely as possible, and the decisions regarding their career paths are adjusted regularly on the basis of various employee assessments (Stor, 2007; Verbruggen, 2010). Such employee assessments are performed for the purpose of promotion, career path development, organization of training or company reorganization. One of the objectives of such employee assessments is to provide information. Organizations rely on such information and use it to improve employee skills as well as try to make the most of their abilities (Armstrong, 1999; Dessler, 2014; Torrington, et.al. 2014). It is important then to develop measurement tools that apply to developing correct employee performance forecasts, as well as to establish the facilitators and inhibitors of employee development in the work environment (cf. Tracz-Krupa, 2016).

From the above arguments, the following hypothesis can be raised:

Hypothesis: The use of the GRM in the process of the assessment of the psychological content of work among employees can provide more precise and more detailed solutions than the use of standard tools of psychological diagnosis.

\section{METHOD}

\subsection{Study participants and procedure}

In order to present the practical application of the GRM, a study was conducted on a sample of 500 employees holding manual positions in a Polish mining company. The study was conducted within a bigger project, whose objective was to improve the working conditions of employees in a selected organization. As the company expressed its willingness to cooperate and its interest in the research findings, the next step was the development of questionnaires and sending them to the company's management board. The questionnaires completed by the employees were gradually returned. The 
participants were randomly chosen from the group of 2000 workers who participated in the obligatory health and safety procedures training, which were conducted in the first quarter of 2016. The group of participants consisted of blue-collar workers only. The main characteristics of the sample are presented in Table 1. The employees completed questionnaires individually or in small groups (consisting of 5-10 people) in a quiet place. The time of completion was 10-20 minutes. The persons collecting the data were provided with the instruction to read them.

Table 1

Sample means and standard deviations

\begin{tabular}{l|c|c|c|c|c}
\hline & N & Mean & Min & Max & S.D. \\
\hline Age & 500 & 42.374 & 27.00 & 59.00 & 8.3581 \\
\hline Job seniority & 500 & 12.388 & 1.000 & 29.00 & 6.7347 \\
\hline
\end{tabular}

Source: own study.

\subsection{Tools - Job Content Questionnaire}

A job content questionnaire with 32 questions diagnosing four aspects of work was used in the study. The questionnaire is a translation of the American research tool Job Content Questionnaire - JCQ by Robert Karasek (1979), which was recently adapted for Polish conditions by Żołnierczyk-Zreda and Bedyńska (2014). The first nine questions in the questionnaire regarding the assessment of decision latitude, i.e. the employees' conviction that they are able to meet the requirements and feel in control of what they are responsible for. Questions 10-18 consider the psychological demands on the employees, such as time pressure, intellectual effort, variety and unpredictability of tasks. Questions 19-24 deal with job insecurity and questions 25-32 relate to the scope of support from the superior and co-workers. R. Karasek's theory regards two qualities of work: the demands and scope of control, i.e, the decision latitude. Consequently, there may be four working situations:

1. low demands - high control,

2. low demands - low control,

3. high demands - high control,

4. high demands - low control.

The last situation is especially difficult for the employee. The author calls it a "high tension situation" (Karasek, 1979). In order to develop and shape employee motivation, it is worth affecting individual elements of work 
content in the following way: by maintaining a rather high level of control, rather high psychological demands along with a sense of work stability and support from the superior and coworkers. The questionnaire is universally used all over the world and its psychometric values are high: reliability in different subscales $-0.70-0.86$, validity -0.68 (Karasek 1979; ŻołnierczykZreda and Bedyńska, 2014).

\section{Graded Response Model}

The features which are directly unobserved (hidden or latent traits) can be measured with a very useful tool called IRT models (Item Response Theory). Initially, IRT models defined the relationships between a latent trait and dichotomous questions (yes/no questions.) Later, IRT models were extended to include polytomous questions (with more than two possible responses). IRT models can be used to assess the relationships between the responses given to the questions and the intensity of a specific trait. These models are characterized by the use of observable behavior (the replies given by the respondents are those observed behavior) to estimate the intensity of a specific latent trait.

IRT models assume that a latent trait has a continuous distribution and its value can be any real number (De Ayala, 1993). Furthermore, it is assumed that the probability of the occurrence of a specific behavior is related to the respondents' trait. At this point another important property of IRT models emerges: namely the way in which the respondents will reply to the questions they are asked depends on the intensity of a specific psychological trait. More generally, this theory can be applied to determine the relationships between the replies provided (observable data) and the psychological traits of the respondents.

The most obvious cause of the development of multi-category models of responses is the fact that the multi-category questions are the most often used questions in different kinds of studies. In order then for the study to be versatile, the IRT models must provide the adequate methods to analyze the collected data. Multi-category questions are more attractive than dichotomous questions as they measure a broader scope of the latent trait which is analyzed. One of the important features of multi-category models of responses is whether the categories are ordinal or nominal. Depending on this, there are different types of models. Bock proposed to analyze the questions with nominal categories (Bock, 1997) with the use of the model known as NRM (Nominal Response Model). On the other hand, the questions with ordinal categories of responses can be analyzed with models such as: PCM (Partial Credit Model), RSC (Rating Scale Model; Andersen, 
1995), GPCM (Generalized Partial Credit Model; Ostini, Nering, 2006), GRM (Graded Response Model; Samejima, 1997). These models are designed for multi-category questions where the categories are arranged in some order, e.g. from the weakest to the strongest.

As a result of the study, the following traits were measured: level of demands, decision latitude, job insecurity and support from the superior and co-workers. For this purpose primarily, the key developed by the questionnaire's author was applied. The responses were coded as follows: 1 - I completely disagree, 2 - I don't agree, 3 - I agree, 4 - I completely agree. Next, the GRM was used to measure the traits being analyzed. In this paper $\theta_{i}$ denotes the parameter related to respondent $i$, indicating the degree of intensity of the analyzed latent trait (Andersen, 1997; Bock, 1997).

All calculations were made with the use of the ltm package in $\mathrm{R}$ program (Rizopoulos, 2010). Extended versions of the latent trait models are also available in the latest eRm package (Hatzinger, Mair, 2007; Koller, Maier, Hatzinger, 2015; Hatzinger, Mair, Maier, 2015). The questions presented to the employees were also analyzed with the use of the ltm package in $\mathrm{R}$ program - four parameters were estimated for each question: three parameters being the threshold values of a given question, denoted in the paper as $\alpha_{j 2}, \alpha_{j 3}, \alpha_{j 4}$ and parameter $\beta_{j}$ denoting discrimination parameter of question $j$ (Andersen, 1995; De Ayala, 1993).

\section{FINDINGS}

In order to achieve the set goal, the collected data were analyzed twice. First, they were analyzed in compliance with the original procedure proposed by the questionnaire's author - Robert Karasek. Table 2 shows the results collected for five randomly selected employees:

Table 2

Points collected by ten employees with the use of the response analysis key

\begin{tabular}{c|c|c|c|c|c}
\hline Employee & $\begin{array}{c}\text { Decision } \\
\text { latitude }\end{array}$ & $\begin{array}{c}\text { Psychological } \\
\text { demands }\end{array}$ & Insecurity & $\begin{array}{c}\text { Superior } \\
\text { support }\end{array}$ & $\begin{array}{c}\text { Co-worker } \\
\text { support }\end{array}$ \\
\hline 1 & 74 & 7 & 6 & 11 & 13 \\
\hline 2 & 56 & 10 & 6 & 12 & 12 \\
\hline 3 & 66 & 11 & 7 & 9 & 10 \\
\hline 4 & 72 & 12 & 4 & 7 & 9 \\
\hline 5 & 56 & 13 & 5 & 13 & 12 \\
\hline
\end{tabular}

Source: own study. 
In the second stage, the data were analyzed with the use of the GRM. Only random results were presented to demonstrate the relation, similarities and differences in the application of the two comparable methods and to draw conclusions.

Tables 3 and 4 show the score of two employees ( 1 and 2) with the same number of points in three categories:

Table 3

Assessment by employee 1

\begin{tabular}{|c|c|c|c|c|}
\hline Category & Response pattern & Points & Estimate of $\theta$ & $\operatorname{SE}(\theta)$ \\
\hline Decision latitude & 314442333 & 72 & 1.608 & 0.18 \\
\hline Psychological demands & 332233233 & 10 & -0.498 & 0.08 \\
\hline Insecurity & 121233 & 5 & -0.141 & 0.04 \\
\hline Superior support & 3323 & 11 & 0.329 & 0.12 \\
\hline Co-worker support & 3233 & 11 & 0.791 & 0.14 \\
\hline
\end{tabular}

Source: own study.

Table 4

Assessment by employee 2

\begin{tabular}{l|l|c|c|c}
\hline \multicolumn{1}{c|}{ Category } & Response pattern & Points & Estimate of $\theta$ & SE $(\theta)$ \\
\hline Decision latitude & 322444414424 & 70 & 1.528 & 0.19 \\
\hline Psychological demands & $\mathbf{3} 3 \mathbf{3} 2 \mathbf{2} \mathbf{3} 3 \mathbf{2} 3$ & $\mathbf{1 0}$ & $\mathbf{- 0 . 2 0 4}$ & $\mathbf{0 . 0 3}$ \\
\hline Insecurity & $\mathbf{1 2} \mathbf{2} 2 \mathbf{2} 3 \mathbf{3}$ & $\mathbf{5}$ & $\mathbf{- 0 . 1 4 1}$ & $\mathbf{0 . 0 3}$ \\
\hline Superior support & $\mathbf{2} 3 \mathbf{3} 3$ & $\mathbf{1 1}$ & $\mathbf{- 0 . 2 6 6}$ & $\mathbf{0 . 0 4}$ \\
\hline Co-worker support & 2233 & 10 & 0.21 & 0.13 \\
\hline
\end{tabular}

Source: own study.

Table 5

Probability of choosing the first, second, third or fourth category for questions 1 to 9 (decision latitude)

\begin{tabular}{c|c|c|c|c}
\hline Question & $P\left(X_{i j}=1\right)$ & $P\left(X_{i j}=2\right)$ & $P\left(X_{i j}=3\right)$ & $P\left(X_{i j}=4\right)$ \\
\hline 1 & 0.019 & 0.089 & 0.781 & 0.111 \\
\hline 2 & 0.222 & 0.721 & 0.044 & 0.013 \\
\hline 3 & 0.003 & 0.042 & 0.866 & 0.089 \\
\hline 4 & 0.008 & 0.140 & 0.785 & 0.067 \\
\hline 5 & 0.004 & 0.079 & 0.814 & 0.103 \\
\hline 6 & 0.051 & 0.351 & 0.553 & 0.045 \\
\hline 7 & 0.009 & 0.074 & 0.811 & 0.106 \\
\hline 8 & 0.057 & 0.497 & 0.411 & 0.035 \\
\hline 9 & 0.056 & 0.396 & 0.524 & 0.024 \\
\hline
\end{tabular}

Source: own study. 
The application of the GRM provides also an opportunity to conduct an analysis of the questions included in the questionnaire.

Tables 5 to 9 present the probability of choosing the first, second, third or fourth category in questions regarding the assessment of demands (Table 5), decision latitude (Table 6), job insecurity (Table 7), support from the superior (Table 8) and from co-workers (Table 9), respectively.

Table 6

Probability of choosing the first, second, third or fourth category for questions 10 to 18 (demand)

\begin{tabular}{c|c|c|c|c}
\hline Question & $P\left(X_{i j}=1\right)$ & $P\left(X_{i j}=2\right)$ & $P\left(X_{i j}=3\right)$ & $P\left(X_{i j}=4\right)$ \\
\hline 10 & 0.008 & 0.250 & 0.619 & 0.123 \\
\hline 11 & 0.007 & 0.239 & 0.697 & 0.057 \\
\hline 12 & 0.021 & 0.285 & 0.591 & 0.103 \\
\hline 13 & 0.016 & 0.509 & 0.446 & 0.029 \\
\hline 14 & 0.017 & 0.405 & 0.519 & 0.059 \\
\hline 15 & 0.007 & 0.303 & 0.633 & 0.057 \\
\hline 16 & 0.009 & 0.324 & 0.596 & 0.071 \\
\hline 17 & 0.003 & 0.168 & 0.728 & 0.101 \\
\hline 18 & 0.019 & 0.346 & 0.576 & 0.059 \\
\hline
\end{tabular}

Source: own study.

Table 7

Probability of choosing the first, second, third or fourth category for questions 19 to 24 (insecurity)

\begin{tabular}{c|c|c|c|c}
\hline Question & $P\left(X_{i j}=1\right)$ & $P\left(X_{i j}=2\right)$ & $P\left(X_{i j}=3\right)$ & $P\left(X_{i j}=4\right)$ \\
\hline 19 & 0.999 & 0.000 & 0.000 & 0.001 \\
\hline 20 & 0.027 & 0.897 & 0.073 & 0.003 \\
\hline 21 & 0.919 & 0.075 & 0.004 & 0.002 \\
\hline 22 & 0.062 & 0.584 & 0.353 & 0.001 \\
\hline 23 & 0.059 & 0.696 & 0.244 & 0.001 \\
\hline 24 & 0.052 & 0.056 & 0.718 & 0.174 \\
\hline
\end{tabular}

Source: own study. 
Table 8

Probability of choosing the first, second, third or fourth category for questions 25 - to 28 (superiors' support)

\begin{tabular}{c|c|c|c|c}
\hline Question & $P\left(X_{i j}=1\right)$ & $P\left(X_{i j}=2\right)$ & $P\left(X_{i j}=3\right)$ & $P\left(X_{i j}=4\right)$ \\
\hline 25 & 0.053 & 0.629 & 0.314 & 0.004 \\
\hline 26 & 0.011 & 0.319 & 0.666 & 0.004 \\
\hline 27 & 0.003 & 0.390 & 0.606 & 0.001 \\
\hline 28 & 0.011 & 0.399 & 0.583 & 0.007 \\
\hline
\end{tabular}

Source: own study.

Table 9

Probability of choosing the first, second, third or fourth category for questions 29 to 32 (co-worker support)

\begin{tabular}{c|c|c|c|c}
\hline Question & $P\left(X_{i j}=1\right)$ & $P\left(X_{i j}=2\right)$ & $P\left(X_{i j}=3\right)$ & $P\left(X_{i j}=4\right)$ \\
\hline 29 & 0.500 & 0.004 & 0.008 & 0.488 \\
\hline 30 & 0.500 & 0.002 & 0.002 & 0.496 \\
\hline 31 & 0.500 & 0.002 & 0.013 & 0.485 \\
\hline 32 & 0.500 & 0.003 & 0.013 & 0.484 \\
\hline
\end{tabular}

Source: own study.

\section{DISCUSSION OF THE FINDINGS}

Table 2 shows the comparison of the scores of ten employees which they received in five areas of the study (insecurity, decision latitude, demands, superior support, co-worker support.) The points were calculated in compliance with the author's unique key. At this stage of the employee assessments, the objective is to compare them in respect to the number of points in specific categories. However, there are employees with the same score, e.g. five employees obtained 5 points in the part of the questionnaire regarding the insecurity level. The comparison of the employees becomes a problem in this respect. Furthermore, a psychological analysis of each employee can also be conducted, taking into account all of their points with the use of Karasek's theory (1979). A detailed psychological analysis, however, is not an objective of this paper. Its main objective is to indicate another tool which can be applied to assess the employee and, at the same time, to conduct a comparative analysis of the employees. That is why the other tables present the results from the analysis of the data collected with the use of the GRM. 
In the next stage of the analysis, two employees were selected. Table 3 and Table 4 show their responses to individual questions and the number of points they scored. Next, the following were estimated for each employee with the use of the 1tm package and the GRM: level of decision latitude, demands, co-worker support and superiors' support (parameter $\theta$ ). Relying on both the points scored with the questionnaire key and on the estimations with the use of the GRM - it is possible to conduct a comparative analysis of the employees that would provide the same results and conclusions - the more points scored by a specific employee (calculated with the use of the 'key') means the higher values of the estimated parameters $\theta$.

These tables show the deliberate comparison of employees who scored the same number of points. A situation where in spite of the different responses given by the employees to the questions asked - they ultimately scored the same number of points - was considered and analyzed and so in the part of the questionnaire regarding the superiors' support the first employee responded to the questions in the following categories: 3323 , whereas the other employee in categories: 2333 . Although ultimately, both employees scored 11 points each, they did not give the same responses. The same employees also scored the same number of points in the part regarding the demands, although the responses of the first employee were: 3322332 33 , whereas those of the other employee were: $\begin{array}{llllllll}3 & 32 & 2 & 3 & 3 & 2 & 3 \text {. When }\end{array}$ analyzing the responses of all 500 employees with the use of the 'key', the same score was often recorded. However, the employers wish to receive all the analyses as detailed as possible so that their results differentiated the respondents, most of whom present a very similar level of predisposition. Consequently, the tools are needed which would differentiate employees. The application of the GRM can be a kind of alternative solution in such situations.

When GRM is used, it is noticeable that the questions demonstrate various discrimination parameters and different threshold values. That is why, although the employees gave the same responses, they demonstrate different estimation levels for specific traits. The following values were achieved: the level of superiors' support for employee 1: 0.329, whereas for employee 2: -0.266 . The estimated level of demands for employee 1: 0.498 , whereas for employee 2: -0.204 . The generation of such diverse results can be useful when conducting a more detailed psychological analysis of the employees.

Although most analyses focus on employees, it is also highly important to gain knowledge of the factors which affect the employees (both negatively 
and positively.) Such analyses can provide a lot of useful information for the organization and enable it to take proper steps to avoid any possible adverse effects.

It is possible to use the GRM to estimate the parameters connected with the questions: threshold values (parameters $\alpha_{j 2}, \alpha_{j 3}, \alpha_{j 4}$ ) and the discrimination parameter (parameter $\beta_{j}$ ). It is possible to calculate the probability of an average employee choosing category $i=1,2,3,4$. An average employee is a respondent with the trait which is analyzed at $\theta=0$.

Tables 5 to 9 show the probabilities of giving responses by an average employee in the first, second, third and fourth category. These calculations were made for all questions in all five parts of the questionnaire. The results generated for all 32 questions are presented in Tables 5-9. Following their comparison it was concluded that:

- regarding decision latitude assessment (Table 5), demands (Table 6) and superiors' support (Table 7) - the third category "I agree" had the highest selection probability,

- regarding insecurity assessment (Table 8): the average employee selected the second category "I don't agree" with the highest probability, with the exception of questions number 19 and 21 where the first response had the highest selection probability,

- regarding the co-worker support assessment (Table 9) - the most often selected categories were the first category "I completely disagree" or the fourth category "I completely agree".

This is important supplementary information for the whole process of analysis of the factors favorable for the development of employees and those which prove difficult for them to perform their work duties. This regards the knowledge of what factors are perceived positively, and which are perceived negatively in a group of employees. The identification of such factors can in turn contribute to the creation of the most favorable work environment and consequently increase the satisfaction and commitment of the employees.

\section{IMPLICATIONS}

A detailed analysis of the results of the job content questionnaire, with the use of the GRM, enabled us to identify specific problems in the scope of the existing working conditions and the employee capabilities.

It was possible to analyze how the employees function with the use of the GRM at two levels. The first area regards the problems at the organization's 
level. The model provides a diagnosis of the difficulties in the scope of work qualities within the following individual subscales:

- freedom in making decisions regarding performing work (decision latitude subscale),

- psychological requirements from the employees set by the employers and job description (psychological demands subscale),

- the sense of employment instability and unclear career path (job insecurity subscale),

- the sense of getting support from both the superior and co-workers (social support subscale).

The other area that could be assessed with the GRM regards individual level. The analysis provides a detailed look at the opinions and capabilities of those who cope very well with the work content and demands, as well as those for whom work is exceptionally challenging, causing tension and a sense of losing control over the operations they must perform. Some responses to the statements in the questionnaire greatly polarized these two groups of employees. A detailed analysis of those responses resulted in developing a kind of instructions for employee development in the scope of specific competences and motivation, in order for them to cope better with their work demands.

The conclusions and recommendations that resulted from the analysis of the findings were then described in detail with the use of the GRM at organization and individual level. The general recommendations and possible solutions of the diagnosed problems were also included.

\subsection{Problems at organization level}

It was possible to identify three problems at organization level on the basis of the analyses' results. The diagnosis was possible due to the analysis of the diversity of the responses in the scope of four qualities of the job content: decision latitude, psychological demands, job insecurity and social support.

The use of the GRM indicated specific statements to which the employees gave highly diverse responses - from a total agreement through to a total negation. Therefore, if a given statement causes highly diverse opinions, it may mean that the job quality described by that statement is not clearly defined and indicates the potential problems of that employee in that area. The selection of statements that cause highly diverse opinions was determined by the values of parameters $\beta_{j}$ (Item Discrimination 
Parameters) estimated with the use of the GRM. Table 10 presents the results - including the statements with the lowest values of the parameter from every analyzed subscale.

Table 10

Statements and estimated values of parameter $\beta_{j}$

\begin{tabular}{l|c|c}
\hline \multicolumn{1}{c|}{ Statement } & Parameter $\beta_{j}$ & Standard error \\
\hline 6 (decision latitude subscale) & 0.359 & 0.061 \\
\hline 14 (psychological demands subscale) & 0.710 & 0.056 \\
\hline 23 (insecurity subscale) & 0.195 & 0.018 \\
\hline 26 (superior support subscale) & 2.591 & 0.278 \\
\hline 29 (coworker support subscale) & 2.191 & 0.274 \\
\hline
\end{tabular}

Source: own study.

The crucial element in decision latitude is the way how the work should be performed. This area, diagnosed by statement 6: "I have little latitude in deciding how my work should be done", is most differentiated among the employees. There are those who feel a lot of latitude in making decisions regarding the performance of their work, and there are those whose latitude is slightly lower, as well as those who feel no latitude at all. As all the employees in the study held positions with a similar scope of duties and responsibilities (miners, mining machine operators, mining blasters, transportation workers), those differences cannot be explained by the different scope of latitude in decision-making because of, e.g. holding different executive positions. Why then do some employees feel they can freely decide how to do their job and others do not? Maybe this is a question of the unclear scope of their duties and responsibilities. It is, however, obvious that such a diverse level of decision latitude results in tension and frustration and it is a potential cause of interpersonal conflict.

Table 11 presents the attitudes of the employees to statement 6 . The respondents were deliberately listed, beginning with those whose level of demands is the lowest going to those with the highest value of the analyzed quality.

The main value of the analysis is the definition of the problem, the identification of its sources and the consequences. This will contribute to further research and finding solutions to the problems regarding decision latitude.

In regard to psychological demands, the most diverse responses were given to the statement regarding the demands set for the employees by other people (statement 14: "I don't deal with contradictory demands from other people at work" - reverse-scoring). 
Table 11

Categories in statement 6 selected by the respondents with various levels of the analyzed quality

\begin{tabular}{c|c}
\hline Statement 6 (selected categories) & Level of decision latitude \\
\hline 3 & -3.042 \\
\hline 2 & -2.497 \\
\hline 2 & -1.638 \\
\hline 2 & 0.042 \\
\hline 1 & 1.608 \\
\hline 3 & 2.117 \\
\hline 4 & 2.486 \\
\hline
\end{tabular}

Source: own study.

Table 12

Selected categories in statement 14 by respondents with various levels of the analyzed quality

\begin{tabular}{c|c}
\hline Statement 14 (selected categories) & Level of psychological demands \\
\hline 1 & -2.261 \\
\hline 2 & -2.049 \\
\hline 3 & -1.979 \\
\hline 3 & 1.543 \\
\hline 4 & 2.406 \\
\hline 3 & 2.595 \\
\hline
\end{tabular}

Source: own study.

This issue regards the conflicting roles of superiors. It turns out that employees frequently face a situation when the superiors from different departments give inconsistent information and instructions that the employees are unable to perform. The characteristics of the work performed by miners require the employees to work in teams of people from different departments. There are miners, machine operators, blasters, drivers and other employees working the same shift. Each of them receives from their immediate superiors specific instructions, which (as it turns out) often contradict the instructions from the shift manager who directly supervises their work. That is why the employees often feel discomfort and frustration, not knowing actually their requirements. Furthermore, they often bring up the consequences (including financial) of insubordination to the superiors' instructions. That problem is then undoubtedly an area which requires organizational changes and it should not be ignored by management. 
In regard to job insecurity, the statement to which the employees gave exceptionally diverse responses was the assessment of professional development and promotion (statement no. 23: "My chances of professional development and promotion are high.") Although in general this part of the questionnaire indicated a rather high job security, the above statement demonstrates problems in the area of understanding and the acceptance of career paths.

Table 13

Categories in statement 23 selected by respondents with various levels of the analyzed quality

\begin{tabular}{c|c}
\hline Statement 23 (selected categories) & Level of job insecurity \\
\hline 1 & -1.878 \\
\hline 3 & -1.041 \\
\hline 1 & -0.125 \\
\hline 3 & 0.074 \\
\hline 2 & 1.208 \\
\hline 3 & 1.909 \\
\hline 1 & 2.332 \\
\hline 2 & 2.773 \\
\hline
\end{tabular}

Source: own study.

Some employees feel that they have the opportunity of professional development, whereas others do not. It might be correctly concluded that such an opinion depends on the length of their service. However, the employees included in the study are qualified specialists who should participate in training in the field of specialist qualifications all the time. In their opinion this is not completely satisfactory and it should be further improved.

In regard to the superior and co-worker support subscale, there were no statements demonstrating a significant diversity in the respondents' opinions. It can be assumed then that, as the results show, most employees feel average support from their superiors and rather high support from their coworkers.

At the end of the analysis of the problems revealed at organization level, it should be noted that the interviews conducted with the employees as an alternative form of research demonstrated exactly the same areas of difficulty regarding work conditions and content. 


\subsection{Problems at individual level}

The other group of conclusions drawn from the analysis with the use of the GRM enables planning activities at individual level. They include activities addressed directly to the employees for whom the requirements of work are very high.

The employees with the highest and the lowest values in the individual scales were compared with the use of the GRM. Their individual answers were compared and the statements that differentiated these two groups of employees were found. The analysis of the statements enables designing individual programs to develop competences and create teams with employees who manage work pressure well and will support and model the behavior of those who find it difficult to cope with the work' demands.

The greatest polarization of the responses in the decision latitude subscale was observed in two statements: 3 - "The work I do requires creativity from me" and 4 - "I can make decisions on my own at my work." The employees with a significantly low latitude level strongly disagree with these two statements compared with the employees with a high latitude level who completely accept them. That means that creative work, where the employees can make decisions on their own, increases the feeling of control of their own actions and consequently creates less stress at work. The results demonstrate that creativity and a participatory management style, including delegating authority and responsibility to employees, should be developed and increased.

Table 14

Categories in statements 3 and 4 selected by respondents with various levels of the analyzed quality

\begin{tabular}{c|c|c}
\hline $\begin{array}{c}\text { Statement 3 } \\
\text { (selected categories) }\end{array}$ & $\begin{array}{c}\text { Statement 4 } \\
\text { (selected categories) }\end{array}$ & Level of decision latitude \\
\hline 1 & 1 & -3.042 \\
\hline 1 & 2 & -2.317 \\
\hline 1 & 1 & -2.289 \\
\hline 2 & 2 & -1.638 \\
\hline 3 & 3 & 0.042 \\
\hline 4 & 4 & 1.608 \\
\hline 4 & 4 & 2.117 \\
\hline 4 & 4 & 2.486 \\
\hline
\end{tabular}

Source: own study. 
The above selection of two statements ( 3 and 4 ) as well as further analysis is explained by the values of parameters $\beta_{j}$ estimated with the use of the GRM. Table 15 presents the results - each statement from the decision latitude subscale is characterized by the Item Discrimination Parameter (parameter $\beta_{j}$ ). Statements 3 and 4 discriminate the employees most. This is confirmed by the highest values of the Item Discrimination Parameters (Table 15) and the analysis of the answers (Table 14).

Table 15

Estimated parameters $\beta_{j}$ for the questions in the decision latitude subscale

\begin{tabular}{l|c|c|c|c|c|c|c|c|c}
\hline Question & 1 & 2 & 3 & 4 & 5 & 6 & 7 & 8 & 9 \\
\hline Parameter & 1.215 & -0.505 & 1.760 & 1.729 & 1.374 & 0.359 & 1.142 & 1.074 & 0.832 \\
\hline Standard error & 0.14 & 0.02 & 0.18 & 0.18 & 0.16 & 0.04 & 0.16 & 0.08 & 0.05 \\
\hline
\end{tabular}

Source: own study.

The psychological demands subscale also demonstrated two statements which greatly polarized the respondents into those who feel high demands and thus work stress, and those who feel their work demands are low so they do not feel work pressure because of that. These statements are: 10 - "My job requires from me working very fast" and 17 - "My job is very unpredictable". Regardless of what the objective qualities of work performed by the respondents are, if they feel it is unpredictable and time pressurerelated, they will be less effective and less motivated to work. The development of time management, prioritizing, and task delegation skills should be considered in this group of employees. Such activities might

Table 16

Categories in statements 10 and 17 selected by respondents with various levels of the analyzed quality

\begin{tabular}{c|c|c}
\hline $\begin{array}{c}\text { Statement 10 } \\
\text { (selected categories) }\end{array}$ & $\begin{array}{c}\text { Statement 17 } \\
\text { (selected categories) }\end{array}$ & $\begin{array}{c}\text { Level of psychological } \\
\text { demands }\end{array}$ \\
\hline 2 & 2 & -2.261 \\
\hline 1 & 2 & -2.049 \\
\hline 2 & 1 & -1.898 \\
\hline 2 & 2 & -1.712 \\
\hline 4 & 4 & 1.543 \\
\hline 4 & 4 & 2.215 \\
\hline 4 & 4 & 2.595 \\
\hline
\end{tabular}

Source: own study. 
Table 17

Estimated parameters $\beta_{j}$ for the questions in the psychological demands subscale

\begin{tabular}{l|c|c|c|c|c|c|c|c|c}
\hline Question & $\mathbf{1 0}$ & 11 & 12 & 13 & 14 & 15 & 16 & $\mathbf{1 7}$ & 18 \\
\hline Parameter & $\mathbf{1 . 4 3 5}$ & 0.996 & 0.741 & 1.020 & 0.710 & 1.141 & 1.272 & $\mathbf{1 . 6 6 6}$ & 0.899 \\
\hline Standard error & $\mathbf{0 . 2 3}$ & 0.08 & 0.14 & 0.18 & 0.06 & 0.18 & 0.19 & $\mathbf{0 . 2 6}$ & 0.12 \\
\hline
\end{tabular}

Source: own study.

contribute to lowering the feeling of high psychological demands, and bring this group of employees closer to those who consider the work demands as being low.

The statement polarizing the respondents into two extreme groups in the job insecurity subscale was: "My job security is high" (question 20). Question 21: "Over the last year, how often have you faced losing your job or being fired?" was the one that also divided the employees into those who marked the response "never" and those who marked the response "all the time." It should be noted, however, that the polarization of the employees was not as strong in that scale as in the previous two because, objectively speaking, job stability in the studied organization is high. This is confirmed by the results of the interviews with the employees and the very good position of the company on the mining sector labor market. The polarization of the results requires a more detailed analysis to identify the reasons for high job insecurity.

Table 18

Categories in statements 20 and 21 selected by respondents with various levels of the analyzed quality

\begin{tabular}{c|c|c}
\hline $\begin{array}{c}\text { Statement 20 } \\
\text { (selected categories) }\end{array}$ & $\begin{array}{c}\text { Statement 21 } \\
\text { (selected categories) }\end{array}$ & Level of job insecurity \\
\hline 1 & 1 & -1.878 \\
\hline 1 & 1 & -1.041 \\
\hline 1 & 2 & -0.125 \\
\hline 2 & 1 & 0.074 \\
\hline 2 & 3 & 1.208 \\
\hline 3 & 2 & 1.509 \\
\hline 3 & 3 & 1.909 \\
\hline 4 & 4 & 2.332 \\
\hline 4 & 3 & 2.618 \\
\hline 3 & 3 & 2.773 \\
\hline
\end{tabular}

Source: own study. 
Table 19

Estimated parameters $\beta_{j}$ for the questions in the insecurity subscale

\begin{tabular}{l|c|c|c|c|c|c}
\hline Question & 19 & 20 & 21 & 22 & 23 & 24 \\
\hline Parameter & 1.328 & 1.672 & 1.935 & 0.370 & 0.195 & 0.388 \\
\hline Standard error & 0.196 & 0.243 & 0.250 & 0.185 & 0.08 & 0.174 \\
\hline
\end{tabular}

Source: own study.

The last subscale - superior and co-worker support - indicated a strong polarization in respect of statements: 27 - "My superior is helpful in performing my job", 31 - "People with whom I work are friendly to me", and 32 - "People with whom I work are helpful in performing my job".

Table 20

Categories in statements 27, 31 and 32 selected by respondents with various levels of the analyzed quality

\begin{tabular}{c|c|c|c}
\hline $\begin{array}{c}\text { Statement 27 } \\
\text { (selected categories) }\end{array}$ & $\begin{array}{c}\text { Statement 31 } \\
\text { (selected categories) }\end{array}$ & $\begin{array}{c}\text { Statement 32 } \\
\text { (selected categories) }\end{array}$ & $\begin{array}{c}\text { Level } \\
\text { of co-worker support }\end{array}$ \\
\hline 1 & 1 & 1 & -2.83 \\
\hline 1 & 1 & 1 & -2.574 \\
\hline 1 & 2 & 2 & -2.056 \\
\hline 2 & 2 & 3 & -1.501 \\
\hline 3 & 3 & 3 & -0.389 \\
\hline 3 & 4 & 3 & -0.231 \\
\hline 4 & 4 & 3 & 1.153 \\
\hline 4 & 4 & 4 & 1.466 \\
\hline 4 & 4 & 4 & 2.329 \\
\hline
\end{tabular}

Source: own study.

Therefore these results demonstrate that some employees feel support from their superiors and co-workers while others do not. Such results may (but do not have to) indicate the existence of hidden conflicts, antipathy or hostile attitude among some employees. Those phenomena should be carefully looked at because they significantly decrease team work efficiency and negatively affect the work atmosphere and commitment.

\section{ORIGINALITY/VALUES}

The analysis conducted with the use of the GRM indicates the significant application value of the method in diagnosing and planning activities in the scope of human capital management and design of healthy workplaces. 
In conclusion, it is worthwhile to add the other articles where the GRM was used for the purpose of a more thorough analysis, the results of this research. Xianhua, Rui, Xiaoling, Yanhong, and Yanbo (2012) decided to explore the IRT graded response model and its application in the patientreported outcomes scale of coronary heart disease. The conclusion was that IRT is a more suitable method to select items for the scale development. Another example of using the GRM in medical sciences could be "NeuroQOL: quality of life item banks for adults with neurological disorders: item development and calibrations based upon clinical and general population testing" (Gershon et al., 2012). The authors used Samejima's Graded Response Model to calculate IRT parameters and then used them for measurements in neurological studies. Finally, Ebesutani et al. (2012) emphasized that the GRM was used as a tool to get better results in psychometric analysis. As it can be seen in the above, the model can be used in many scientific disciplines and enables more detailed analyses.

\section{CONCLUSIONS}

The analyses presented in the paper demonstrated the possible application of the GRM in the employee development improvement process. In light of the above thesis, the most important conclusions are the following:

- the analyses conducted with the use of the proposed method demonstrated the similarities between the results achieved with the use of the questionnaire key and with the use of the model,

- the lists presented in the tables show that analyzing data with the use of the GRM can improve the psychological analyses, especially in order to compare employees who scored the same number of points according to the key,

- as the use of research methods to differentiate candidates is currently very popular, it seems reasonable to suggest the use of the GRM for this purpose,

- in order to address the needs of people facing a decision-making dilemma, the proposed model can support the process of identifying the factors affecting employee development and health, as well as the most favorable work environment. 


\section{REFERENCES}

Andersen, E. B., Polytomous Rasch Models and their estimation, [in:] Fischer, G. H., Molenaar, I. W., Rasch Models: foundations, recent developments and applications, pp. 217-291. SpringerVerlag, New York 1995.

Armstrong, M., A Handbook of Human Resource Management Practice. Kogan Page, United States, 1999.

De Ayala, R. J., An introduction to polytomous item response theory models, "Measurement and Evaluation in Counseling and Development", no. 25, pp. 172-189, 1993.

Bock, R. D., The nominal categories model, [in:] van der Linden, W. J., Hambleton, R. K., Handbook of modern item response theory, pp. 33-49. Springer, New York 1997.

Dessler, G., Human Resource Management, 14 ${ }^{\text {th }}$ ed. Pearson Education, Harlow 2014.

Ebesutani, C., Regan, J., Smith, A., Reise, S., Higa-McMillan, C., Chorpita, C. F, The 10-item positive and negative affect schedule for children, child and parent shortened versions: application of Item Response Theory for more efficient assessment, "Journal of Psychopathology and Behavioral Assessment", no. 34, pp. 191-203, 2012.

Gershon, R. C., Lai, J. S., Bode, R., Choi, S., Moy, C., Bleck, T., Miller, D., Peterman, A., Cella, D., Neuro-QOL: quality of life item banks for adults with neurological disorders: item development and calibrations based upon clinical and general population testing, "Quality of Life Research", no. 21, pp. 475-486, 2012.

Hatzinger, R., Mair, P., Extended Rasch modeling: the eRm package for the application of IRT models, "Journal of Statistical Software", vol. 20, no. 9, pp. 1-20, 2007.

Hatzinger, R., Mair, P., Maier, M., Extended Rasch Modeling (December 12, 2015). Available at: http://erm.r-forge.r-project.org/.

Karasek, R., Job demands, job decision latitude and mental strain: implication for job redesign, “Administrative Science Quarterly”, no. 24, pp. 285-308, 1979.

Koller, I., Maier, M. J., Hatzinger, R., An Empirical Power Analysis of Quasi-Exact Tests for the Rasch Model: Measurement Invariance in Small Samples, "Methodology", vol. 11, no. 2, pp. 45-54, 2015.

Molek-Winiarska D., Stress Management Intervention Assessment - field study results, "International Journal of Contemporary Management", no. 4, pp. 91-109, 2016.

Ostini, R., Nering, M. L., Polytomous Item Response Theory Models, "Sage University Paper Series on Quantitative Applications in the Social Sciences", Series no. 07-144, Sage, Thousand Oaks, 2006.

Rizopoulos, D., An R Package for Latent Variable Modeling and Item Response Theory Analyses, "Journal of Statistical Software", no. 17(5), pp. 1-25, 2007.

Samejima, F., Graded Response Model, [in:] van der Linden, W. J., Hambleton, R. K., Handbook of modern item response theory, pp. 85-100. Springer, New York 1997.

Stor, M., Strategies for Managing the Managerial Staff of International organizations, "Human Resources Management", Polish Academy of Sciences. Institute of Labor and Social Studies, vol. 59, no. 7, pp. 7-27, 2007.

Tracz-Krupa, K., Employee Development within the European Social Fund in Poland. Preliminary research findings, [in:] Rank, S., International Human Resource Management: Concepts and Research, pp. 49-63. Shaker Verlag, Aachen 2016. 
Torrington, D., Hall, L., Taylor, S., Atkinson C., Human Resources Management. $9^{\text {th }}$ ed. Pearson Education, Harlow, 2014.

Verbruggen, M., Career Counseling in the New Career Era, "Review of Business and Economics", no. 10, pp. 2-22, 2010.

Żołnierczyk-Zreda, D., Bedyńska S., Psychometric properties of the Polish version of Karasek's Job Content Questionnaire, "International Journal of Occupational Safety and Ergonomics", vol. 20, no. 4, pp. 583-593, 2014.

Xianhua, Z., Rui, M., Xiaoling, G. Yanhong, L., Yanbo, Z., Application of IRT Graded Response Model in Coronary Heart Disease PRO Scale, "Chinese Journal of Health Statistics", 5, pp. 639-641, 2012.

Received: June 2016, revised: June 2017 